\title{
Fabrication of silver nanoparticles from leaf extract of Butea monosperma (Flame of Forest) and their inhibitory effect on bloom-forming cyanobacteria
}

\author{
Venkatesh Chaturvedi ${ }^{1}$ and Pradeep Verma ${ }^{2 *}$
}

\begin{abstract}
Background: Silver nanoparticles (SNPs) are used extensively in areas such as medicine, catalysis, electronics, environmental science, and biotechnology. Therefore, facile synthesis of SNPs from an eco-friendly, inexpensive source is a prerequisite. In the present study, fabrication of SNPs from the leaf extract of Butea monosperma (Flame of Forest) has been performed. SNPs were synthesized from 1\% leaf extract solution and characterized by ultraviolet-visible (UV-vis) spectroscopy and transmission electron microscopy (TEM). The mechanism of SNP formation was studied by Fourier transform infrared (FTIR), and anti-algal properties of SNPs on selected toxic cyanobacteria were evaluated.
\end{abstract}

Results: TEM analysis indicated that size distribution of SNPs was under 5 to $30 \mathrm{~nm}$. FTIR analysis indicated the role of amide I and II linkages present in protein in the reduction of silver ions. SNPs showed potent anti-algal properties on two cyanobacteria, namely, Anabaena spp. and Cylindrospermum spp. At a concentration of $800 \mu \mathrm{g} / \mathrm{ml}$ of SNPs, maximum anti-algal activity was observed in both cyanobacteria.

Conclusions: This study clearly demonstrates that small-sized, stable SNPs can be synthesized from the leaf extract of B. monosperma. SNPs can be effectively employed for removal of toxic cyanobacteria.

Keywords: Silver nanoparticles (SNPs); Butea monosperma; Cyanobacteria; Anti-algal

\section{Background}

Nanotechnology is an emerging branch of science which deals with synthesis and characterization of various metallic and non-metallic nanoparticles of different compositions, sizes, and shapes [1]. Nanoparticles are molecular aggregates ranging from 1 to $100 \mathrm{~nm}$ in diameter [2,3]. Nanoparticles are being extensively used in areas such as medicine, catalysis, electronics, environmental science, and biotechnology [4]. Among various types of nanoparticles available, silver nanoparticles (SNPs) are the most commonly employed as they are simple to produce following reduction of silver nitrate [5]. Further, silver has been known for its excellent antimicrobial properties and

\footnotetext{
* Correspondence: vermaprad@yahoo.com

${ }^{2}$ Department of Microbiology, Central University of Rajasthan, N.H. 8

Bandarsindri, Kishangarh, Ajmer, Rajasthan 305801, India

Full list of author information is available at the end of the article
}

employed as an antiseptic agent in the treatment of wounds and burns [1,2]. There are many physical and chemical methods for the synthesis of SNPs, such as chemical and photochemical reactions [6], thermal decomposition of metal compounds [7], microwaveassisted reduction [8], and laser-mediated reduction [9]. These methods have several demerits specifically high cost and toxicity in the biological system [10]. Recently, biological synthesis of SNPs by employing different plant extracts is considered as an inexpensive and eco-friendly method for large-scale production of SNPs $[10,11]$. Most of the plants employed for the reduction process also exhibit medicinal properties [12,13]. Butea monosperma Lam. Kuntze (Fabaceae) is a plant, which is native to India and is called Flame of Forest because it forms orange-colored flowers during the summer season (April to June). This plant is of great medicinal 
importance to the native people. Leaves of this plant exhibit anti-inflammatory activity and are also used to control giardiasis caused by the protozoa Giardia lamblia [14]. To date, there is no report on the synthesis of SNPs using this plant.

Cyanobacteria are primitive photosynthetic bacteria, which are considered as an excellent source of pigments, vitamins, polysaccharides, proteins, pharmaceuticals, and other biologically active compounds [15-17]. However, there are certain cyanobacteria that are responsible for the production of algal blooms. Algal blooms cause depletion of dissolved oxygen in water leading to anoxia and subsequently death of fishes. These cyanobacteria also produce various toxins (microcystin, saxitoxin, etc.) which are extremely toxic to mammals including humans $[18,19]$. Therefore, there is urgent need to identify chemicals and metabolites which inhibit algal bloom formation [18]. Recent studies have demonstrated that silver nanoparticles can inhibit bloom formation by the toxin-producing cyanobacteria Microcystis aeruginosa [19]. However, there is no report on the impact of SNPs on other toxic cyanobacteria. In the present study, an attempt has been made to synthesize and characterize SNPs from the leaf extract of $B$. monosperma owing to its medicinal properties. Further, the anti-algal potential of SNPs on two toxic bloom-forming cyanobacteria, namely, Anabaena spp. and Cylindrospermum spp., was also evaluated.

\section{Methods}

\section{Synthesis of SNPs}

Fresh leaves of B. monosperma growing in forests of Bilaspur, Chhattisgarh, India, were collected (Figure 1). Fresh leaves were washed extensively with water followed by final wash with distilled water. The veins of the leaves were removed and cut into small pieces $\left(1 \mathrm{~cm}^{2}\right)$. One gram $(1 \mathrm{~g})$ of leaf pieces was suspended in $100 \mathrm{ml}$ of

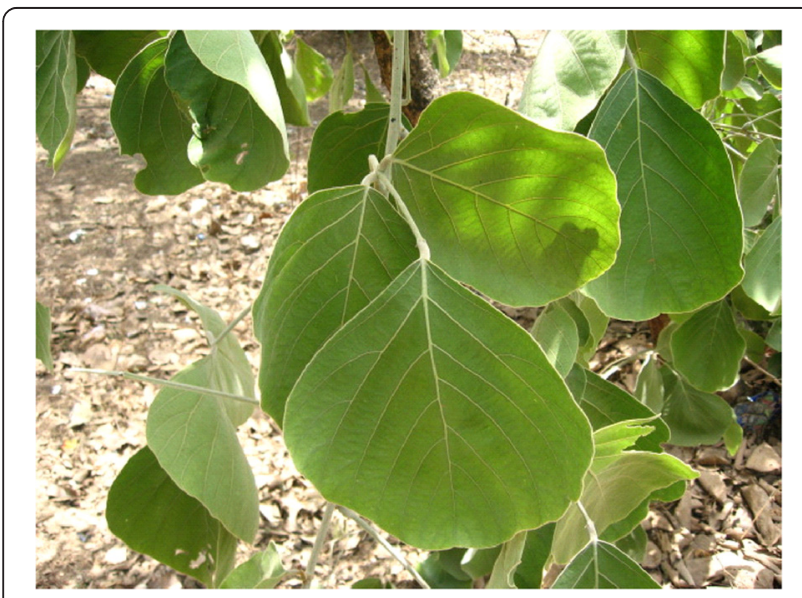

Figure 1 The photograph of Butea monosperma (Flame of Forest) plant. double distilled water and heated on a water bath for $20 \mathrm{~min}$. After heating, the extract was filtered using filter paper (Whatman filter paper no. 1) and stored at $4^{\circ} \mathrm{C}$ until further use. For synthesis of SNPs, different dilutions of the leaf extract in double distilled water were prepared, and to it, $0.01 \mathrm{M}$ of $\mathrm{AgNO}_{3}$ solution was added. The solution was incubated in a rotary shaker at $100 \mathrm{rpm}$ for 2 to $3 \mathrm{~h}$ in the dark.

\section{Characterization of SNPs by UV-vis spectroscopy and TEM}

Synthesis of SNPs was monitored using a double-beam spectrophotometer (Systronics 2203, Systronics, Ahmedabad, India). The absorption spectrum in the range of 200 to $800 \mathrm{~nm}$ of the $0.5 \%$ leaf extract solution and the $1 \%$ leaf extract solution containing $0.01 \mathrm{mM} \mathrm{AgNO}_{3}$ was recorded. The presence of SNPs was confirmed by observing a peak at 410 to $430 \mathrm{~nm}$, corresponding to the surface plasmon resonance of SNPs. The $1 \%$ leaf extract solution mixed with $100 \mathrm{ml}$ of Millipore water (Millipore Corporation, Billerica, MA, USA) was employed as a positive control. The particle size and distribution of SNPs were determined by transmission electron microscopy (TEM) analysis. For TEM analysis, a drop of the solution containing $1 \%$ leaf extract solution supplemented with $0.01 \mathrm{mM} \mathrm{AgNO}{ }_{3}$ was employed. TEM was performed using a Morgagni 268D transmission electron microscope (FEI Electron Optics, Hillsboro, OR, USA). Size distribution of SNPs from the TEM image was calculated by the software ImageJ.

\section{Organism and culture conditions}

In the present study, the two organisms employed were Anabaena spp. and Cylindrospermum spp. (blue-green freshwater cyanophyte). Both the cyanobacterial strains were obtained from the Department of Life Sciences, Guru Ghasidas Vishwavidyalaya, Bilaspur (Chhattisgarh). For maintenance of cultures, BG-11 medium [20] was employed. The cultures used were maintained in BG-11 medium in a culture room at $26^{\circ} \mathrm{C}$ to $30^{\circ} \mathrm{C}$ with a $16 / 8$-h photoperiod under 3,000 lx from a cool white light. The cultures were hand shaken daily at least twice to keep the organisms in a homogeneous state.

\section{Growth measurements}

Growth of the organisms was monitored spectrophotometrically (double-beam spectrophotometer, Systronics 2203) at regular intervals with increase in absorbance at $660 \mathrm{~nm}[20]$.

\section{Pigment extraction from cyanobacteria Sample preparation}

Culture sample $(5.0 \mathrm{ml})$ was withdrawn, and cells were centrifuged at $4,800 \mathrm{rpm}$ for $5 \mathrm{~min}$. The supernatant obtained was removed, and the cell pellet was then resuspended in $5.0 \mathrm{ml}$ of distilled water to remove any salts that 
A

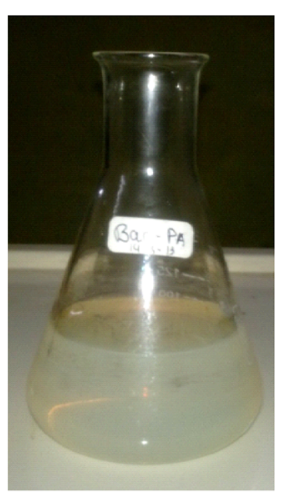

B

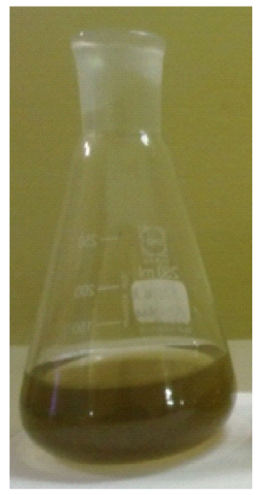

C

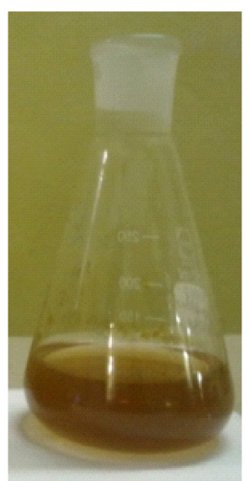

Figure 2 Synthesis of SNPs using different leaf extract concentrations. (A) Control flask containing $0.01 \mathrm{M} \mathrm{AgNO}_{3}$. (B) Visible color change in $0.01 \mathrm{M} \mathrm{AgNO}_{3}$ solution after addition of $0.5 \%$ leaf extract solution. (C) Visible color change in $0.01 \mathrm{M} \mathrm{AgNO}_{3}$ solution after addition of $1.0 \%$ leaf extract solution.

could have been retained with the biomass, and again centrifuged [21].

\section{Extraction and quantification}

The solvent absolute methanol (99\%) was used for pigment extraction. Briefly, cells were suspended in $5.0 \mathrm{ml}$ of solvent followed by vortexing for $15 \mathrm{~s}$ and incubated for $20 \mathrm{~min}$. In the absence of other cell wall disruption methods, the cells were centrifuged at 4,000 rpm for $5 \mathrm{~min}$. The absorbance of the supernatant obtained was read spectrophotometrically at the wavelength corresponding to the equations [21].

\section{Chlorophyll- $a$ and carotenoid determination}

For chlorophyll-a and carotenoid determination, the pellet obtained was kept and the supernatant was discarded, and to the pellet, $5.0 \mathrm{ml}$ of $25 \%$ absolute methanol was added and it was incubated at $50^{\circ} \mathrm{C}$ for $1 \mathrm{~h}$. The sample was then centrifuged at $4,000 \mathrm{rpm}$ for $5 \mathrm{~min}$, and the clear supernatant obtained was used for measuring optical density in an ultraviolet-visible (UV-vis) spectrophotometer at 663 and $480 \mathrm{~nm}$, respectively [22]. Protein determination was performed using the modified Lowry method [23].

\section{Anti-algal properties of SNPs}

After synthesis of SNPs, the solution was centrifuged at $12,000 \mathrm{rpm}$ for $30 \mathrm{~min}$ at $30^{\circ} \mathrm{C}$, and the nanoparticle pellet was collected, washed twice with $5 \mathrm{ml}$ of Millipore water, and dried in a hot air oven. For toxicity studies, a stock solution of SNPs $(5 \mathrm{mg} / \mathrm{ml})$ was prepared. SNPs were suspended by sonicating the solution at $40 \mathrm{kHz}$, with a pulse rate of 40 for $10 \mathrm{~min}$. The stock was stored in the dark at $4^{\circ} \mathrm{C}$ prior to use. Cells were taken $(50 \mathrm{ml}$ from the 7 -day-old

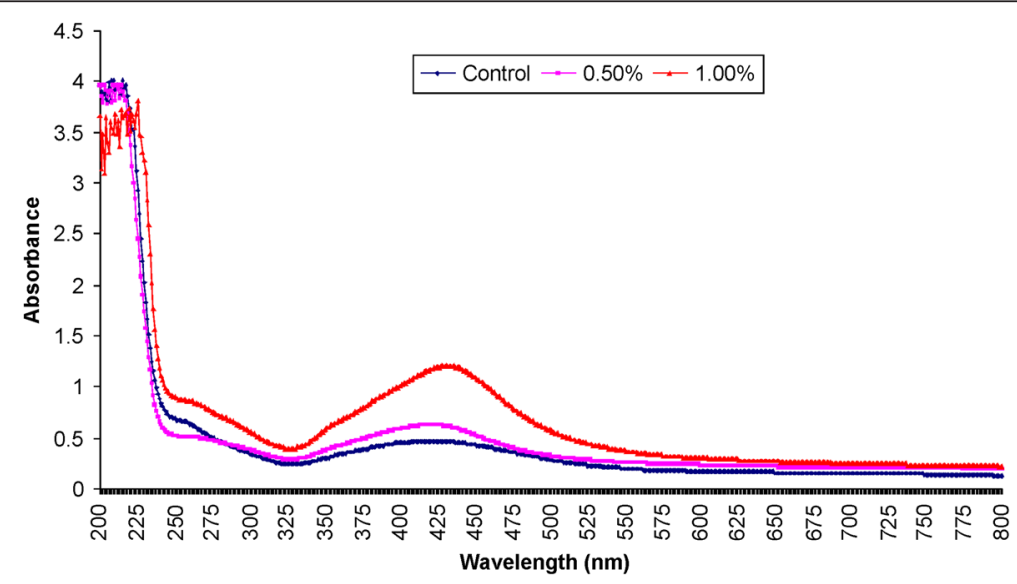

Figure $3 \mathrm{UV}$-vis spectrum of leaf extract and $\mathrm{AgNO}_{3}$ solutions. The figure shows the UV-vis spectrum of different concentrations of the leaf extract solution $(0.5 \%$ and $1 \%)$ in the presence of $0.01 \mathrm{M} \mathrm{AgNO}_{3}$ solution after $3 \mathrm{~h}$ of incubation. 


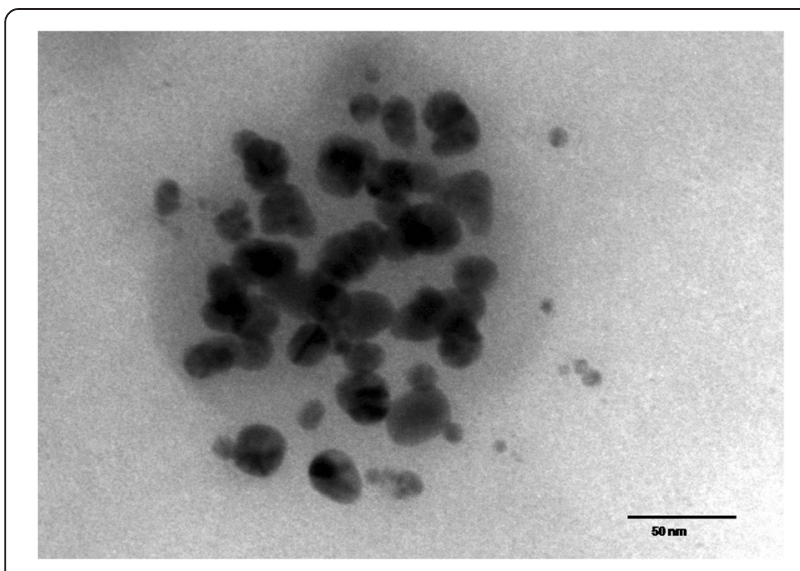

Figure 4 TEM image of synthesized SNPs using Butea monosperma (Flame of Forest), 1\% leaf extract solution.

culture) and transferred aseptically into four sets of 100-ml Erlenmeyer flasks for each strain. Different concentrations of SNPs $(400,600$, and $800 \mu \mathrm{g} / \mathrm{ml})$ were added into each flask except for one, which was kept as control, and flasks were incubated in a culture room at $26^{\circ} \mathrm{C}$ to $30^{\circ} \mathrm{C}$ with a $16 / 8$-h photoperiod under 3,000 lx from a cool white light for 15 days. Periodic analysis was done (0th, 4th, 8th, and 12th day) by harvesting the cells from each set of flasks, followed by evaluation of its effect on growth and protein and pigment content of the cyanobacterial cells. All the experiments were performed in triplicate, and results were represented as mean \pm standard deviation. The results were compared by one-way ANOVA followed by the Tukey-Kramer comparison test.

\section{Results and discussion}

\section{Synthesis of SNPs}

There are several reports on the synthesis of SNPs from plants having high medicinal and ornamental value, such as Aloe vera [24], Cinnamomum camphora [25], Azhadirachta indica [26], and Ocimum sanctum [27]. B. monosperma is an ornamental and medicinal plant, native to mountainous regions of India. Almost all the parts of the plant have medicinal value. The leaves show diuretic and

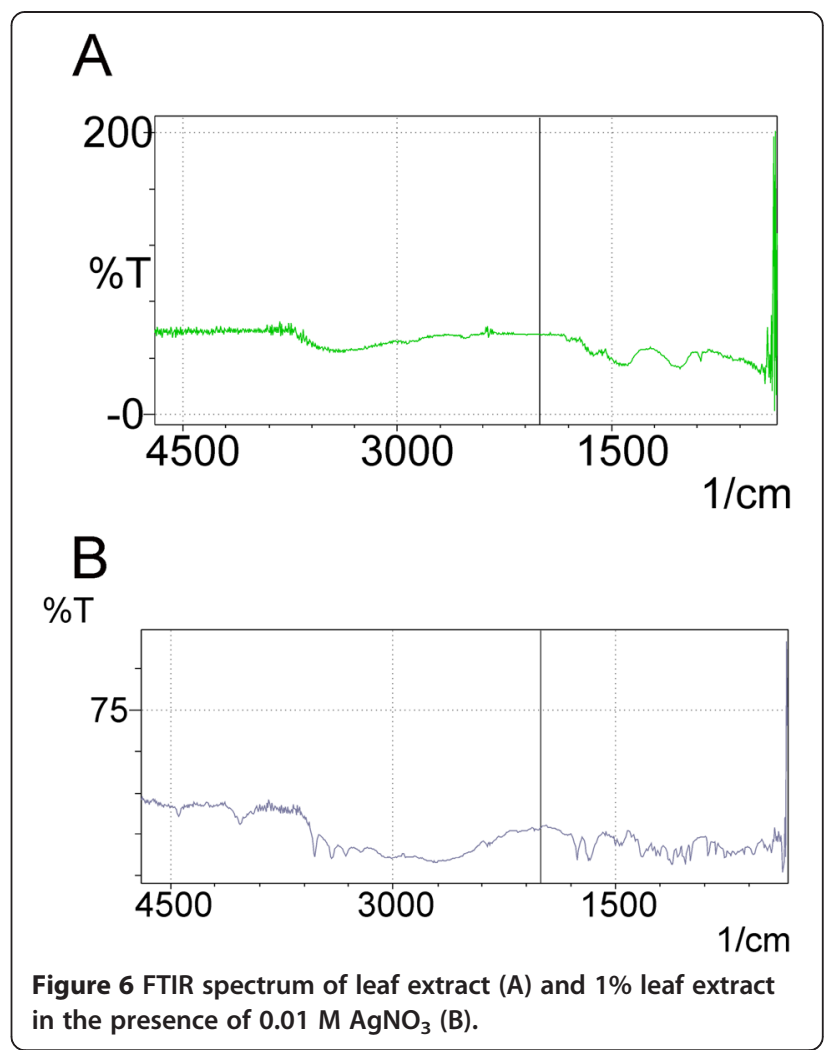

anti-ovulatory properties [14]. In this study, the synthesis of SNPs was carried out by employing the leaf extract of $B$. monosperma. The method was optimized by varying the concentration of the leaf extract $(0.5 \%, 1.0 \%)$ with a fixed concentration $(0.01 \mathrm{M})$ of $\mathrm{AgNO}_{3}$. After the reaction, the synthesis was confirmed by a dark brown color of the solution. Studies have shown that during reduction of silver ions by the leaf extract, the solution first turns yellow and in later stages turns dark brown. The dark brown color represents the most stable form of SNPs, whereas the gray color represents instability and aggregation of SNPs $[1,10]$. In this study, at a concentration of $0.05 \%$ leaf extract, the color of the solution was yellow but it turned grayish after some time (Figure 2B). At a concentration of $1.0 \%$ leaf extract, the solution was yellow in the beginning and turned

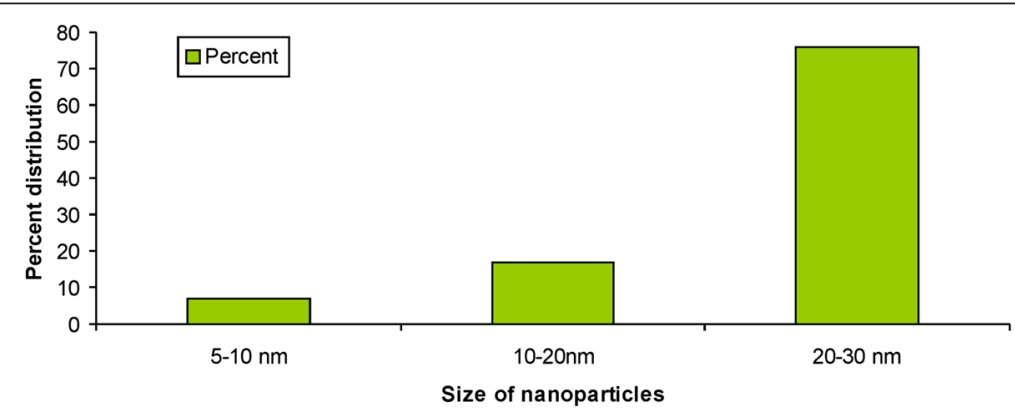

Figure 5 Size distribution of SNPs. 
dark brown on standing (Figure 2C). This demonstrates that stable SNPs are produced at this concentration.

\section{Characterization of SNPs}

Chemically synthesized silver nanoparticles were characterized by UV-vis spectroscopy and TEM. The UV-visible spectrum of the leaf extract and $\mathrm{AgNO}_{3}$ solutions is shown in Figure 3. It is clear from the spectrum that at $0.5 \%$ leaf extract solution, the peak at 420 to $430 \mathrm{~nm}$ was low and broad, suggesting instability of the nanoparticles. At a concentration of $1.0 \%$ leaf extract solution, the peak was comparatively high and less broad, suggesting the stability and small size of the silver nanoparticles $[28,29]$. High absorbance indicates higher concentration of SNPs. At $0.5 \%$ leaf extract concentration, the peak was observed at $420 \mathrm{~nm}$. At 1.0\% leaf extract concentration, the peak shifted to $430 \mathrm{~nm}$. This redshift has been attributed to the increase in the size of nanoparticles. The greater is the shift, the larger is the size of nanoparticles [30]. However, in the present study, the shift was not very high (420 to $430 \mathrm{~nm}$ ), and it indicates the small size of SNPs.
In order to further confirm SNP formation, TEM was performed. The photograph of TEM is shown in Figure 4. It is clear from the figure that nearly spherical SNPs were formed. From the TEM images, particle size and distribution were calculated. The results are depicted in Figure 5. It was observed that majority of the nanoparticles (76\%) were in the range of 20 to $30 \mathrm{~nm}, 17 \%$ were in the range of 10 to $20 \mathrm{~nm}$, and 7\% were in the range of 5 to $10 \mathrm{~nm}$. These results clearly represent that the size distribution of nanoparticles falls under 5 to $30 \mathrm{~nm}$, with the major portion under the 20- to 30-nm range. By employing this method, the size distribution of SNPs obtained was smaller when compared to previous reports, viz. 44 to $225 \mathrm{~nm}$ using Pergularia daemia plant latex [31] and 71 to $110 \mathrm{~nm}$ using mangrove plant Avicennia marina [32].

\section{FTIR analysis of SNPs}

To elucidate the role of various functional groups present in the leaf extract in the synthesis of SNPs, Fourier transform infrared (FTIR) analysis of the leaf extract and
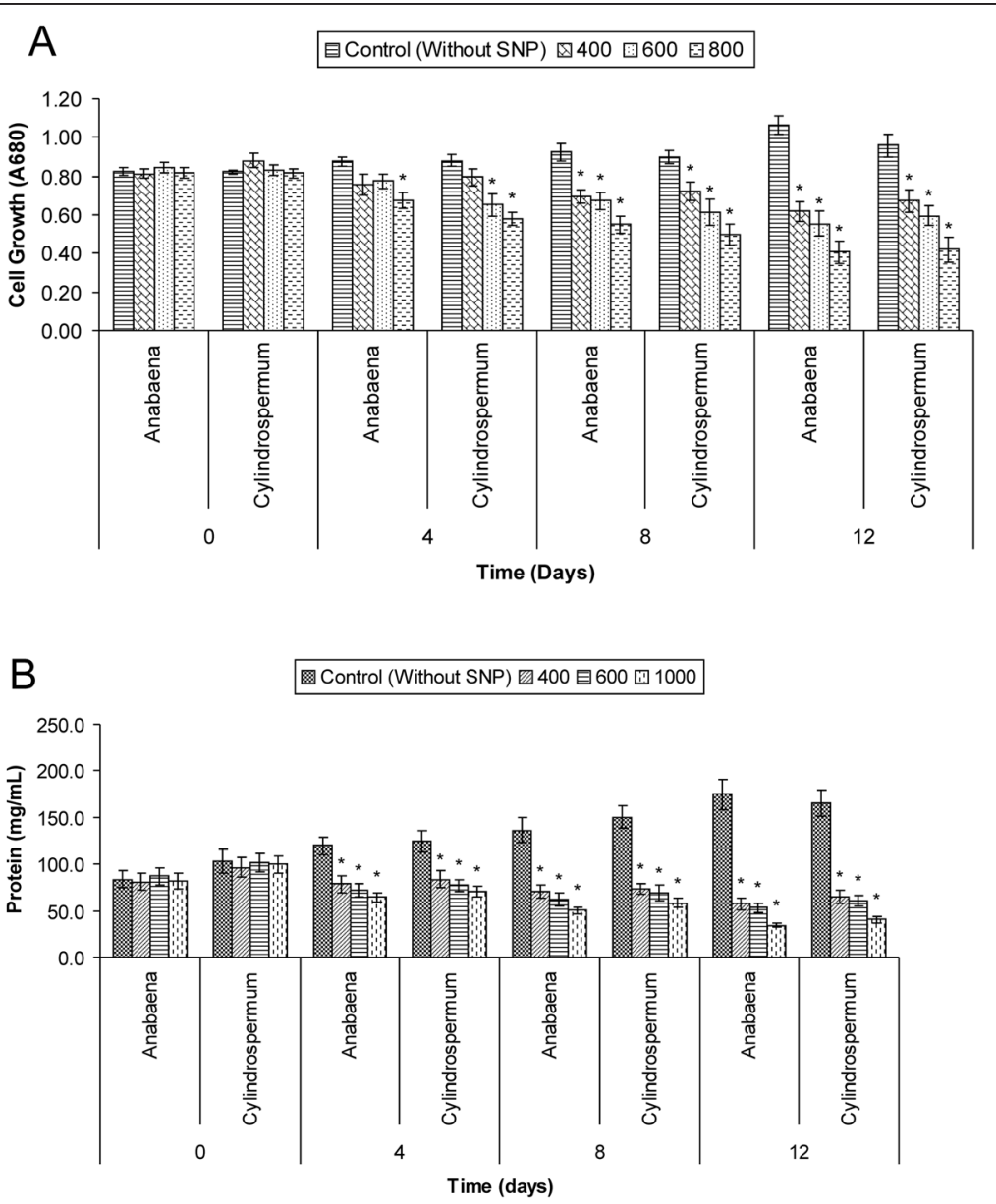

Figure 7 Inhibitory activity of different concentration of SNPs $(400,600$, and $800 \mu \mathrm{g} / \mathrm{ml})$ on Anabaena spp. and Cylindrospermum spp. (A) Cell growth and (B) protein. The asterisk denotes significance at $p \leq 0.01$. 
$\mathrm{AgNO}_{3}$ was carried out (Figure 6A,B). It is clear from the spectrum that in the presence of $\mathrm{AgNO}_{3}$, broadening of peaks in the $1,680 \mathrm{~cm}^{-1}$ and $3,450 \mathrm{~cm}^{-1}$ regions suggests a plausible role of amide I and II linkages present in protein in the reduction of silver ions. The broadening of these peaks was not evident in the FTIR spectrum of the leaf extract. This result is in agreement with previous reports which suggest the involvement of proteins present in the plant extract in the reduction of silver ions [29].

\section{Evaluation of anti-algal properties of SNPs on cyanobacteria}

Cyanobacterial blooms are defined as intense growth of cyanobacteria in water bodies [18]. Algal blooms occur in natural waters when cyanobacteria grow quickly in water due to the presence of high amounts of nitrogen and phosphorus present due to eutrophication. A dense algal bloom can block sunlight and take up oxygen in the water, killing aquatic plants and animals. Some cyanobacteria produce cyanotoxins that severely affect animals and humans. Some common bloom-forming cyanobacteria are Anabaena, Cylindrospermopsis, Nodularia, Oscillatoria, Microcystis, and Planktothrix [33,34]. The current scenario demands development of efficient methods to control growth of these cyanobacteria. Various chemical methods have been employed such as treatment with copper sulfate and ozone, chlorination, or potassium permanganate. These methods have shown little efficacy; they are costly and their application to water bodies is sometimes practically not feasible [35]. In the present investigation, use of SNPs to control growth of cyanobacteria has been evaluated. There are numerous reports on the antimicrobial nature of SNPs [36]. The antimicrobial nature of silver/silver ions can be attributed to their ability to bind and denature proteins causing
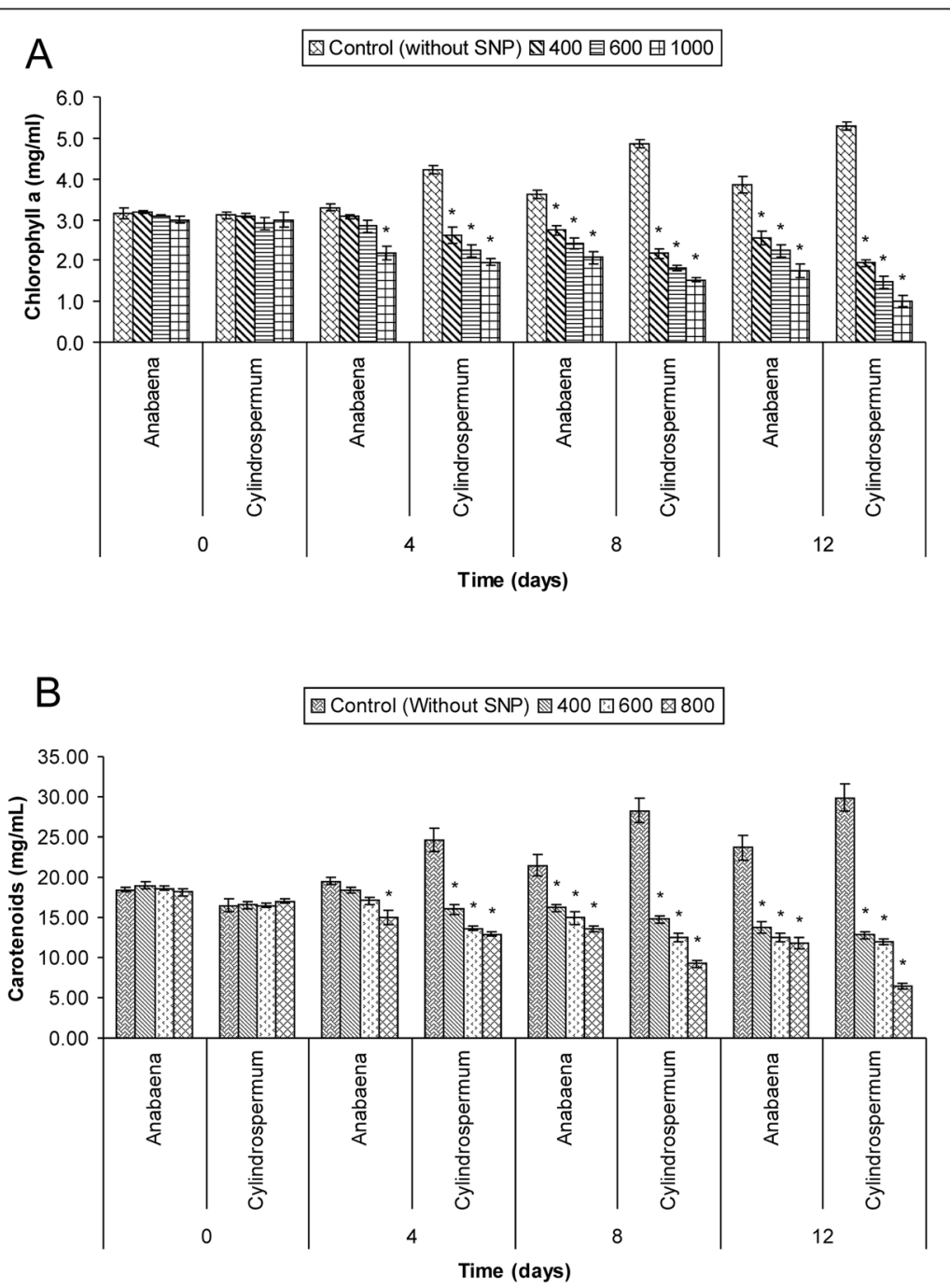

Figure 8 Inhibitory activity of different concentration of SNPs $(400,600$, and $800 \mu \mathrm{g} / \mathrm{ml})$ on Anabaena spp. and Cylindrospermum spp. (A) Chlorophyll-a and (B) carotenoid. The asterisk denotes significance at $p \leq 0.01$. 
structural changes in the cell wall and nuclear membrane, leading to cell death. Silver ions can also inhibit bacterial replication by binding to DNA [2]. The antialgal activity of SNPs on the toxic bloom-forming cyanobacteria $M$. aeruginosa has been reported (park). However, studies pertaining to the effect of SNPs on other cyanobacteria are still in the primitive stage. In the present study, the anti-algal activity of SNPs on two cyanobacteria, namely, Anabaena spp. and Cylindrospermum spp., was evaluated. The different concentrations of silver nanoparticles, i.e., 400, 600, and $800 \mu \mathrm{g} /$ $\mathrm{ml}$, were employed to assess the anti-algal property in the two cyanobacteria. Pre-grown cultures of cyanobacteria were incubated with different concentrations of SNPs. A similar culture without SNPs served as control. After a regular time interval of 4 days, growth, protein concentration, and chlorophyll-a and carotenoid content were estimated and compared (Figures 7 and 8). It is clearly evident from the results that dose-dependent reductions in the above mentioned parameters were observed in the two cyanobacteria. In both the cyanobacteria, significant inhibition $(p \leq 0.01)$ was observed at a concentration of $800 \mu \mathrm{g} /$ $\mathrm{ml}$ of SNPs. When toxicity of both cyanobacteria was compared, it was observed that Anabaena spp. was more sensitive towards SNPs than Cylindrospermum spp. The anti-algal activity remarkably increased with increasing concentrations of SNPs. The results were in agreement with the results obtained by Park et al. [19] where SNPs showed a dose-dependent inhibition on the harmful cyanobacterium $M$. aeruginosa. Yamanka et al. [3] proposed two hypotheses to explain the antimicrobial (here in this case, it is anti-algal) activity of SNPs. Initially, a cell in contact with SNPs takes up nanoparticles inside the cell, which inhibit various enzymes and biological processes causing severe damage to the cell. Secondly, reactive oxygen species (ROS) are also produced, possibly through the inhibition of respiratory enzymes, and attack the cell causing cell death.

\section{Conclusions}

In this study, SNPs using the leaf extract of B. monosperma (Flame of Forest) were synthesized. It was observed that at a concentration of $1 \%$ leaf extract, synthesis of stable, small-sized SNPs took place. TEM analysis indicated that the size distribution of SNPs was under 5 to $30 \mathrm{~nm}$, which is smaller as compared to previous reports. SNPs showed strong anti-algal properties on two cyanobacteria, namely, Anabaena spp. and Cylindrospermum spp. A direct dosedependent relationship between concentration of SNPs and cell death was observed. SNPs have been previously shown to be antimicrobial in nature. The antimicrobial activity of SNPs on different bacteria and fungi has been reported. Results of the present study clearly demonstrate that SNPs can be used for control of toxic cyanobacteria.
However, this is preliminary study where toxicity was assessed in laboratory conditions. It is essential to test the feasibility of this method in natural environments and to develop a method for the application of SNPs to water bodies.

\section{Competing interests}

The authors declare that they have no competing interests.

\section{Authors' contributions}

VC carried out the synthesis and characterized the anti-algal properties of SNPS on cyanobacteria. PV designed the whole study and prepared the manuscript. Both authors read and approved the final manuscript.

\section{Acknowledgements}

PV is thankful to DBT for providing the financial support (Grant No. BT/304/NE/ TBP/2012)

\section{Author details}

${ }^{1}$ School of Biotechnology, Banaras Hindu University, Varanasi, UP 221005, India. ${ }^{2}$ Department of Microbiology, Central University of Rajasthan, N.H. 8 Bandarsindri, Kishangarh, Ajmer, Rajasthan 305801, India.

Received: 23 December 2014 Accepted: 31 March 2015 Published online: 16 April 2015

\section{References}

1. Lengke FM, Fleet EM, Southam G (2007) Biosynthesis of silver nanoparticles by filamentous cyanobacteria a from a silver(I) nitrate complex. Langmuir 23:2694-2699

2. Prabhu S, Poulose EK (2012) Silver nanoparticles: mechanism of antimicrobial action, synthesis, medical applications, and toxicity effects. Int Nano Lett 2:32

3. Yamanaka M, Hara K, Kudo J (2005) Synergistic bactericidal activity of silver nanoparticles and ciprofloxacin against phytopathogens. Appl Environ Microbiol 71(11):7589-7593

4. Sadowski Z (2010) Biosynthesis and Application of Silver and Gold Nanoparticles, In: David Pozo Perez (Ed.), Silver Nanoparticles, Rijeka, Croatia, InTech, pp 257-276

5. Rai M, Yadav A, Gade A (2009) Silver nanoparticles as a new generation of antimicrobials. Biotech Adv 2:776-83

6. An C, Peng S, Sun Y (2010) Facile synthesis of sunlight-driven AgCl:Ag plasmonic nanophotocatalyst. Adv Mater 22(23):2570-2574

7. Wang RC, Gao YS, Chen SJ (2009) Simple synthesis and size-dependent surface enhanced Raman scattering of Ag nanostructures on $\mathrm{TiO} 2$ by thermal decomposition of silver nitrate at low temperature. Nanotechnology 20 (37):375605

8. Horikoshi S, Abe H, Torigoe K, Abe M, Serpone N (2010) Access to small size distributions of nanoparticles by microwave-assisted synthesis. Formation of $\mathrm{Ag}$ nanoparticles in aqueous carboxymethylcellulose solutions in batch and continuous-flow reactors. Nanoscale 2(8):1441-1447

9. Peng Z, Spliethoff B, Tesche B, Walther T, Kleinermanns K (2006) Laser-assisted synthesis of Au-Ag alloy nanoparticles in solution. J Phys Chem B 2110 (6):2549-2554

10. Murugan K, Senthilkumar B, Senbagam D, Al-Sohaibani S (2014) Biosynthesis of silver nanoparticles using Acacia leucophloea extract and their antibacterial activity. Int J Nanomedicine 9:2431-2438

11. Rahimi-Nasrabadi M, Pourmortazavi SM, Shandiz SA, Ahmadi F, Batooli H (2014) Green synthesis of silver nanoparticles using Eucalyptus leucoxylon leaves extract and evaluating the antioxidant activities of extract. Nat Prod Res 27:1-6

12. Rajasekharreddy P, Rani PU (2014) Biofabrication of Ag nanoparticles using Sterculia foetida L. seed extract and their toxic potential against mosquito vectors and HeLa cancer cells. Mater Sci Eng C Mater Biol Appl 39:203-212

13. Suresh G, Gunasekar PH, Kokila D, Prabhu D, Dinesh D, Ravichandran N, Ramesh B, Koodalingam A, Vijaiyan Siva G (2014) Green synthesis of silver nanoparticles using Delphinium denudatum root extract exhibits antibacterial and mosquito larvicidal activities. Spectrochim Acta A Mol Biomol Spectrosc 127:61-66

14. Burlia DA, Khadeb AB (2007) A comprehensive review on Butea monosperma (Lam.) Kuntze. Pharmacogn Rev 1:333-7 
15. Pulz O, Gross W (2004) Valuable products from biotechnology of microalgae. Appl Microbiol Biotechnol 65:155-165

16. Rastogi RP, Richa SRP, Singh SP, Hader DP (2010) Photoprotective compounds from marine organisms. J Ind Microbiol Biotechnol 37:537-558

17. Singh SP, Kumari S, Rastogi RP, Singh KL, Richa SRP (2010) Photoprotective and biotechnological potentials of cyanobacterial sheath pigment, scytonemin. Afr J Biotechnol 9(5):580-588

18. Humpage AR, Hardy SJ, Moore EJ, Frosscio SM, Falcones IR (2000) Microcystins (cyanobacterial toxin) in drinking water enhances the growth of aberrant cryptic foci in the mouse colon. J Toxicol Environ Health part A 61:155-165

19. Park MH, Kim KH, Lee HH, Kim JS, Hwang SJ (2010) Selective inhibitory potential of silver nanoparticles on the harmful cyanobacterium Microcystis aeruginosa. Biotechnol Lett 32(3):423-428

20. Chaturvedi V, Chandravanshi M, Rahangdale M, Verma P (2013) An integrated approach of using polystyrene foam as an attachment system for growth of mixed culture of cyanobacteria with concomitant treatment of copper mine waste water. J Waste Management doi:10.1155/2013/282798

21. Henriques M, Silva A, Rocha J (2007) Extraction and Quantification of Pigments from a Marine Microalga: A Simple and Reproducible Method. In: Mendez-Vilas A. (Ed.), Communicating Current Research and Educational Topics and Trends in Applied Microbiology, Badajoz, Spain, Formatex, pp. 586-593.

22. Jodlowska S, Latala A (2011) The comparison of spectrophotometric method and high-performance liquid chromatography in photosynthetic pigments analysis. OnLine J Bio Sci 11(2):63-69

23. Markwell MA, Haas SM, Tolbert NE, Bieber LL (1981) Protein determination in membrane and lipoprotein samples: manual and automated procedures. Methods Enz 72:296-303

24. Chandran SP, Chaudhary M, Pasricha R, Ahmad A, Sastry M (2006) Synthesis of gold nanotriangles and silver nanoparticles using Aloe vera plant extract. Biotechnol Prog 22:577-583

25. Huang $Q$, Li D, Sun Y, Lu Y, Su X, Yang H, Wang Y, Wang W, Shao N, Hong J, Chen C (2007) Biosynthesis of silver and gold nanoparticles by novel sundried Cinnamomum camphora leaf. Nanotechnology 18:105104

26. Lalitha A, Subbaiya R, Ponmurugan P (2013) Green synthesis of silver nanoparticles from leaf extract Azhadirachta indica and to study its antibacterial and antioxidant property. Int J Curr Microbiol App Sci 2:228-235

27. Singhal G, Bhavesh R, Kasariya K, Sharma AR, Singh RP (2011) Biosynthesis of silver nanoparticles using Ocimum sanctum (Tulsi) leaf extract and screening its antimicrobial activity. J Nanopar Res 13:2981-2988

28. Mohanta YK, Behera SK (2014) Biosynthesis, characterization and antimicrobial activity of silver nanoparticles by Streptomyces sp. SS2. Bioprocess Biosyst Eng. doi:10.1007/s00449-014-1205-6

29. Ajitha B, Ashok Kumar Reddy Y, Sreedhara Reddy P (2014) Biosynthesis of silver nanoparticles using Plectranthus amboinicus leaf extract and its antimicrobial activity. Spectrochim Acta A Mol Biomol Spectrosc 128:257-262

30. Ashkarran AA, Bayat A (2013) Surface plasmon resonance of metal nanostructures as a complementary technique for microscopic size measurement. Int Nano Lett 3:50

31. Patil CD, Borase HP, Patil SV, Salunkhe RB, Salunke BK (2012) Larvicidal activity of silver nanoparticles synthesized using Pergularia daemia plant latex against Aedes aegypti and Anopheles stephensi and nontarget fish Poecillia reticulate. Parasitol Res 111(2):555-562

32. Gnanadesigan M, Anand M, Ravikumar S, Maruthupandy M, Syed Ali M, Vijayakumar V, Kumaraguru AK (2011) Antibacterial potential of biosynthesized silver nanoparticles using Avicennia marina mangrove plant. Appl Nanosci 2:143-147

33. Carmichael WW (2001) Health effects of toxin producing cyanobacteria: the cyanoHABs. Hum Ecol Risk Assess 7:1393-1407

34. Codd GA, Morrison LF, Metcalf JS (2005) Cyanobacterial toxins: risk management for health protection. Tox Appl Phar 203:264-272

35. Westrick J, Szlag D, Southwell B, Sinclair J (2010) A review of cyanobacteria and cyanotoxins removal/inactivation in drinking water treatment. Anal Bional Chem 397:1705-1714

36. Banerjee P, Satapathy M, Mukhopahayay A, Das P (2014) Leaf extract mediated green synthesis of silver nanoparticles from widely available Indian plants: synthesis, characterization, antimicrobial property and toxicity analysis. Biores Bioproc 1:3

\section{Submit your manuscript to a SpringerOpen ${ }^{\odot}$ journal and benefit from:}

- Convenient online submission

- Rigorous peer review

- Immediate publication on acceptance

- Open access: articles freely available online

- High visibility within the field

- Retaining the copyright to your article

Submit your next manuscript at $\gg$ springeropen.com 